\title{
En torno al contexto de producción del códice neoyorquino de la Primera Partida (HSA, HC397/573)
}

\author{
On the production context of Primera Partida's New York manuscript (HSA, \\ HC397/573)
}

\author{
Ricardo Pichel \\ ricardo.pichel@uah.es \\ Universidad de Alcalá, España
}

Recepción: 23 Abril 2021

Aprobación: 18 Agosto 2021

Publicación: 01 Noviembre 2021

Cita sugerida: Pichel, R. (2021). En torno al contexto de producción del códice neoyorquino de la Primera Partida (HSA, HC397/573). Olivar, 21(34), e110. https://doi.org/10.24215/18524478e110

\begin{abstract}
Resumen: Este artículo ofrece un estudio arqueológico del manuscrito HC397/573 de la Hispanic Society of America (Nueva York), que transmite una versión mixta de la Primera Partida y del Setenario de Alfonso X. El examen codicológico, paleográfico y escripto-lingǘstico nos permite inferir el marco cronológico, geográfico y sociocultural en el que se pudo haber gestado este particular testimonio.
\end{abstract}

Palabras clave: Alfonso X, Primera Partida, Filología material, Corona de Aragón, Siglo XIV.

\begin{abstract}
This article offers an archaeological study of the manuscript HC397/573 of the Hispanic Society of America (New York), which transmits a mixed version of the Primera Partida and the Setenario of Alfonso X. The codicological, paleographic and scriptolinguistic exam allows us to infer the chronological, geographic and sociocultural frame in which this particular manuscript could have been created.
\end{abstract}

Keywords: Alfonso X, Primera Partida, Hispanic Society of America, Material Philology, Crown of Aragon, 14th century.

En memoria de Fabián Landi y en agradecimiento a su valiosa labor en la Hispanic Society of America.

El manuscrito HC397/573 de la Hispanic Society of America (HSA) de Nueva York ${ }^{2}$ se hallaba en Leipzig a principios del siglo xx en manos del librero anticuario Karl W. Hiersemann (1854-1928), quien en 1911 publica en su catálogo $\mathrm{n}^{\circ} 397$ una breve ficha descriptiva del códice, seguida de un folleto aparte encargado al prof. Wilhelm R. Friedmann - en el que se ofrece de manera sumaria una primera aproximación filológica al manuscrito y se reproduce la transcripción de algunos fragmentos. ${ }^{3}$ Una copia del registro catalográfico de Hiersemann ( ${ }^{\circ}$ 575) se encuentra adherida al fol. 1r del códice y en él se recoge - a doble columna, en español e inglés- una descripción básica del manuscrito, su precio ${ }^{4}$ y algunas observaciones posiblemente extractadas del folleto de W. Friedmann. En cuanto a este último, anunciado al final de la ficha de Hiersemann, ${ }^{5}$ se trata de un opúsculo de 17 páginas sin numerar — a doble columna, en alemán e inglésen el que primero se presenta el manuscrito y se destaca la trascendencia del código legal alfonsí y de su historia textual (pp. 1-3), para después ofrecer lo que constituye la primera aproximación filológica al texto del códice 
neoyorquino (pp. 4-17). Tras la distribución del catálogo y del opúsculo de Friedmann entre sus potenciales compradores, finalmente el códice es adquirido poco tiempo después (ca. 1911-1914) por el coleccionista y bibliófilo Archer M. Huntington (1870-1955) — con quien ya mantenía una relación comercial desde finales del xix - ${ }^{6}$ engrosando así su espléndida biblioteca hispánica ubicada en el Alto Manhattan donde hoy se conserva en el Departamento de Manuscritos y Libros Raros de la Hispanic Society of America.

El códice neoyorquino de la Primera Partida (HS1) fue descrito por Antonio García y García en unas breves notas publicadas en Anuario de Historia del Derecho Español (1963b), y más tarde por Charles B. Faulhaber (1983) en el primer volumen del catálogo de los manuscritos de la HSA (cf. Philobiblon, BETA manid 1115). En este trabajo se actualiza esta información y, a través de un estudio arqueológico del ejemplar, se ofrecen nuevos datos que contribuyen a desentrañar en gran medida el contexto - cronológico, geográfico y, tal vez, sociocultural y político- de producción de este valioso testimonio de la Primera Partida alfonsí.

\section{El estudio de la tRadición teXtual De HS1}

En el marco de los sucesivos ensayos de reelaboración (post)alfonsí de las Siete Partidas, el texto transmitido por HS1 remite, de acuerdo con Jerry Craddock (1986; cf. 2008), a la primera de las redacciones (1256-1265) del autodenominado Libro del fuero de las leyes, estrechamente relacionada con el Espéculo (BETA texid 1052) y representada también por los códices LBL (British Library, Add. 20787; BETA manid 1112) y ZAB (Archivo y biblioteca Francisco de Zabálburu, Vitrina; BETA manid 1105) de la Primera Partida. ${ }^{7}$ Sin embargo, al mismo tiempo, el uso e influencia del Setenario (BETA texid 1028) en este manuscrito revela una tentativa de refundición de las dos tradiciones - legalista y sapiencial $-{ }^{8}$ en las que se encuadran progresivamente las varias redacciones de las Partidas (la primera por una parte, y la segunda y tercera por otra), conectando, además, con la postrera fase de reelaboración alfonsí. De este modo, se trataría de un estadio evolutivo ulterior e híbrido al transmitir una refundición inconclusa de la Primera Partida con interpolaciones del Setenario, último eslabón este del continuo proceso de reescritura por parte del rey Sabio cuya incorporación en HS1 constituye, además, el único testimonio conocido de su recepción legal.9

El pionero estudio de W. Friedmann (1911), en el que se cotejan sumariamente los cinco primeros títulos, especialmente el tercero y el quinto, con varios testimonios - en especial ZAB - y con la edición de la Real Academia de la Historia (1807), abrió el camino a investigaciones posteriores tras la adquisición del códice por Huntington, aunque habría que esperar poco más de medio siglo hasta que el manuscrito volviera a suscitar interés. A raíz de su estancia en la HSA, García y García (1963a: 526-527; 1963b) pudo estudiar y comparar los 26 títulos que transmite HS1 con los otros dos testimonios antes citados (LBL y ZAB), detectando así las principales variantes estructurales (omisiones, repeticiones, desdoblamientos y adiciones textuales), especialmente en el caso del título quinto (De los sagramentos de santa eglesia), en el que se registra una treintena de leyes sin correspondencia en los otros dos testimonios colacionados. Una década después, Juan Antonio Arias Bonet (1972) actualizó sumariamente el estudio de García y García, reparando también en la estrecha relación con el Setenario y en particular en las secciones del título $5^{\circ}$ reproducidas por el profesor salmantino.

Actualmente, continúa pendiente un estudio filológico exhaustivo del contenido de esta refundición en el que se ponga particular atención, entre otras cuestiones, a la relación del texto principal con las interpolaciones del Setenario, así como a las numerosas notas coetáneas que revisan, completan y corrigen buena parte del texto, especialmente los ocho primeros títulos (cf. infra). Además de los primeros estudios, ya citados, de Friedmann (1911), García y García (1963b) y Arias Bonet (1972), en las últimas décadas el códice neoyorquino y sus particularidades textuales han sido objeto de consideración en varios trabajos de investigación, entre los que cabe citar los ensayos de Craddock (1981; 1986, p. 56, n. Ah60; 1992; 2001, xlivxlv; 2008), García y García (1986, p. 692, n. 80), Díez de Revenga Torres y Puche Lorenzo (2003), Rodríguez 
Velasco (2010), Pérez Martín (2014), Panateri (2016, 2017, 2018, 2020, 2021), Panateri y Tostes (2021) o Puigdengolas (2021).

En cuanto al propio texto del manuscrito, pese a la publicación de Ramos Bossini (1984), lo cierto es que todavía resulta imprescindible una nueva edición del texto, ya que el trabajo del profesor granadino, aunque en la altura meritorio, contiene muchos errores de transcripción ${ }^{10}$-en no pocos casos desvirtuando la variedad lingüística de la copia (cf. infra n. 24) - y la exigua información aportada en la introducción resulta errónea o desacertada (cf. Iglesia Ferreirós 1985, p. 953; Craddock, 2001, xliv). De hecho, parecen más fiables los extractos incorporados en los estudios de Friedmann (1911) —fragmentos de los títulos 3 y 5- y García y García (1986) -índice general, rúbrica del prólogo, fragmentos de los títulos 2, 3, 4, 5, 6, 8, 10, 11, 14, 15, 18 y 19-. En la actualidad Daniel A. Panateri prepara una nueva edición del manuscrito, complementando y actualizando el estudio de sus conexiones con el Setenario, con el Ordenamiento de Alcalá y con la obra de Brunetto Latini.

\section{CONSERVACIÓN, ESTRUCTURA Y ORgANIZACIÓN INTERNA DEL MANUSCRITO}

Por fortuna, el contenido del manuscrito se ha conservado prácticamente íntegro. Las únicas lagunas materiales registradas en el códice se sitúan en el último cuaderno, donde el extravío de un bifolio supuso una pequeña pérdida textual en los títulos 24 (leyes 12-16, la mitad de la 11 y el inicio de la rúbrica de la 17) y 26 (la última ley y parte de la penúltima). Más allá de esta falta puntual, el estado de conservación actual del códice es medianamente defectuoso, pues la unión de los cuadernos se ha debilitado bastante y los primeros y últimos folios (fols. 1-4 y 183-185) presentan un deterioro avanzado a causa de diferentes agentes externos (especialmente la humedad y la polilla). Algunos rotos puntuales en los fols. 24-25 (margen de pliegue inferior) y 55 (el ángulo superior externo fue remendado con unos pequeños trozos de papel blanco encolados en el recto). Algunos márgenes externos, aunque no afecta a la lectura, están parcialmente deteriorados por el paso del tiempo (fol. 36).

El texto comienza en el verso del primer folio con un índice de títulos y leyes (ausente en la edición de Ramos Bossini, 1984; cf. García y García, 1963b: 18-19), seguido del prólogo cuya rúbrica abarca la mitad inferior de la segunda columna de esta página. Curiosamente el recto del primer folio no recibió escritura y parece que actuó desde un principio como cubierta propiamente dicha del primer cuaderno.

El códice presenta 184 folios agrupados en 10 cuadernos (fols. 1-26, 27-54, 55-72, 73-90, 91-110, 111-126, 127-143, 144-161, 162-181 y 182-185), todos ellos conservados íntegramente salvo el último, como se ha dicho. Los cinco primeros son mixtos, compuestos por un bifolio externo en pergamino y un cuerpo cartáceo de 9, 10 o 14 bifolios. Los restantes cuadernos son todos en papel, aunque reforzados en su pliegue interno por una tira de pergamino - reaprovechado - cosida al fascículo (cf. infra). Los cuadernos más extensos son los dos primeros, de 13 y 14 bifolios; con 10 bifolios los cuadernos 5 y 9; con 9 bifolios los cuadernos 3 , 4 y 8 ; por último, con 8 bifolios los cuadernos 6 y 7 (fórmula de colación: $1^{26} 2^{28} 3^{18} 4^{18} 5^{20} 6^{16} 7^{16} 8^{18} 9^{20} 10^{6-2}$ ). El décimo y último fascículo constituye un binión en la actualidad, pero en origen era un ternión del que no conservamos el bifolio externo (fols. [181bis]-[185bis]), como se puede apreciar en la Fig. 1. García y García (1963b, p. 332) suponía la pérdida de varios folios entre el 181 y el 182, pero si tenemos en cuenta el texto faltante (poco más de cinco leyes) es presumible el extravío de un único folio, que formaría bifolio con la última del cuaderno. 
FIG. 1

Estructura del cuaderno 10 del ms. HSA, HC397/573

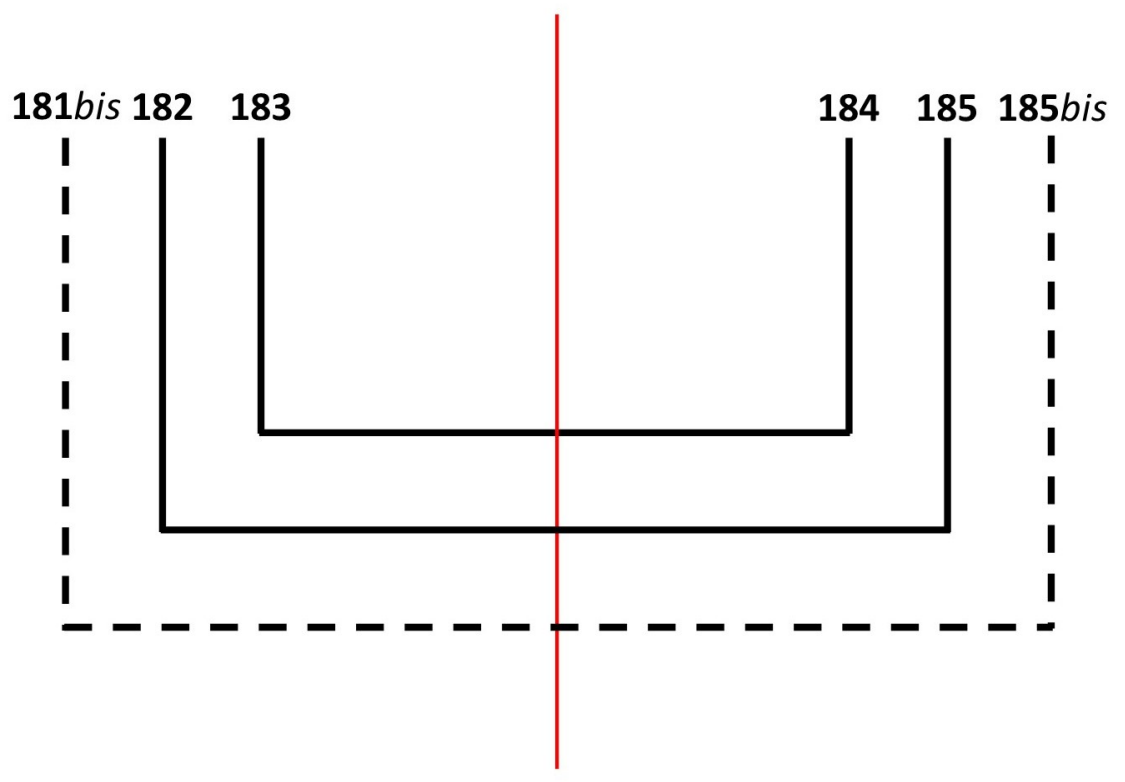

Todos los cuadernos, excepto el último, presentan reclamos coetáneos incluidos por los dos calígrafos principales del texto (cf. infra): "pasa ligeramente" (fol. 26v), "Sintiese" (fol. 54v), "postulaçion" (fol. 72v), "cantares" (fol. 90v), "sagrada" (fol. 110v), "ffaçer sin" (fol. 126v), "fiestas enlas capiellas" (fol. 143v), "Ley .xa . por que razon" (fol. 161v), "-uento Mas delo que era quando" (fol. 181v). Las variaciones con respecto al incipit correspondiente del reclamo son mínimas; ${ }^{11}$ únicamente en un caso (fol. 90v "cantares") no se incorporó el texto del reclamo al inicio del folio siguiente (fol. 91r: "e por señales"). El reclamo del fol. 181v ("-uento Mas delo que era quando") nos muestra el comienzo de la laguna textual del último cuaderno. Todos los reclamos están dispuestos en horizontal —en el ángulo inferior interno del vuelto-, salvo el del fol. 54v, cuya orientación es vertical. El estilo de las cartelas es sobrio: ovalada o rectangular simple y de color pardo o negro desvaído (fols. 90v, 110v, 181v; en este último caso, el trazado es discontinuo), rectangular simple y de trazado rojo (fols. 126v, 143v), o ambas (fol. 54v); en otros casos la cartela rectangular roja es doble y aparece adornada con trazos circulares en las esquinas (fol. 161v) o presenta un leve marco interno y ovalado en tinta parda (fols. 26v, 72v). No se advierten vestigios de signaturas o de otros elementos de ordenación intra o interfascicular.

No se conserva foliación o paginación antigua. Solo consta una foliación a lápiz de finales del siglo XIX o comienzos del XX (debida posiblemente a Hiersemann) en el ángulo inferior externo del recto de los folios. Hay un error de foliación en el cuaderno 7: no se consignó el fol. 139, por lo que se salta del 138 al 140 (aunque no hay laguna textual). En cambio, la foliación ininterrumpida del último fascículo indica que la laguna del bifolio [181bis]-[185bis] es quizás anterior a la llegada del códice a Alemania.

\section{SOPORTE Y MISE EN PAGE}

El soporte utilizado es mayoritariamente papel de trapo afiligranado, probablemente de origen italiano, no hispanoárabe procedente de Granada, como se indica en la ficha catalográfica de Hiersemann (1911) y que luego reproducen García y García (1963b, p. 270) y Ramos Bossini (1984, [lvii]). Se trata de un papel bastante recio y consistente, con dos tipos de filigrana: fruto con dos hojas (en los dos primeros cuadernos: fols. 1-54) y arco con flecha (en los restantes folios); en ambos casos la filigrana se sitúa más o menos equidistante entre el 
segundo y tercer corondel del folio ${ }^{12}$ (en el caso del arco, los extremos sobresalen unos $15 \mathrm{~mm}$ a cada lado). En el primer caso, se trata de una pera (higo o granada, en algunos repertorios), en posición vertical y ligeramente curvada, acompañada de dos hojas laterales de tamaño medio y con forma semitriangular, situadas a la misma altura que el fruto y cuyos tallos rematan en un pequeño anillo inferior; el fruto, con forma abombada, presenta dos pequeñas protuberancias en la parte superior (Fig. 2). En algunos folios se registra una variante muy similar a la descrita, pero con una de las hojas más alargada y estrecha (Fig. 3). En el caso del arma, se trata de un arco tensado, en posición vertical y sin anillo inferior, con un lomo poco ondulante de trazado doble, atravesado por una flecha de longitud media y con punta triangular (Fig. 4).

Filigranas en el ms. HSA, HC397/573: fruto (variantes 2 y 3 ) y arco (4)
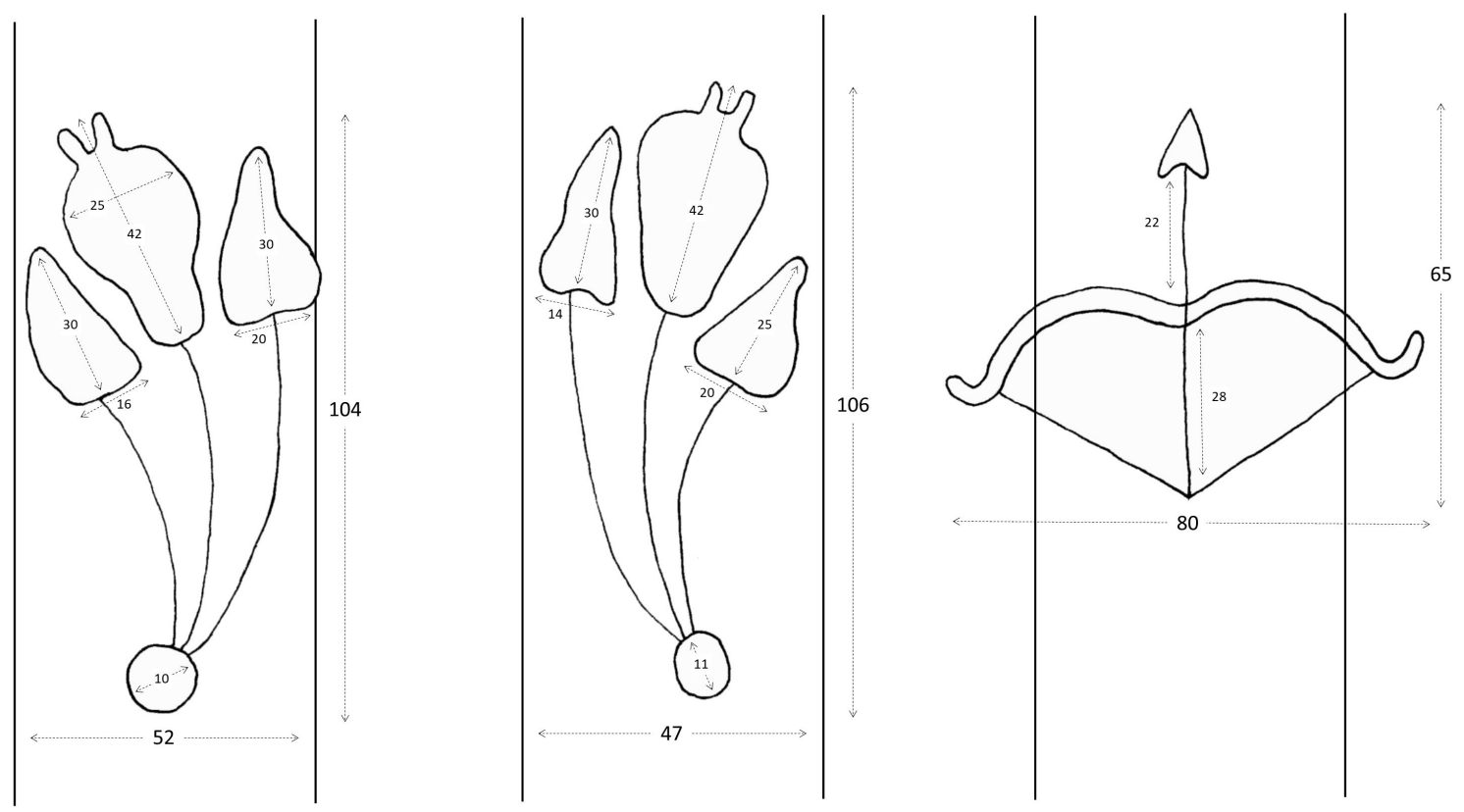

Faulhaber (1983, p. 226) identificó las filigranas más parecidas en los catálogos de Valls i Subirà (1970) y Briquet (1991), fechadas entre la tercera década del siglo XIV y la segunda del XV (ca. 1331-1419). Es posible limitar este arco cronológico teniendo en cuenta la evolución de las dos figuras a lo largo del Trescientos e identificando con mayor exactitud las variantes más similares en los diferentes repertorios de filigranas disponibles. En el caso del fruto, nuestra filigrana debe situarse en la franja de 1350-1380, pues no es hasta mediados de siglo (no antes de 1350) y, especialmente, durante las décadas de 60 y 70, cuando comienzan a registrarse las variantes con las dos hojas laterales un poco más grandes, siendo ca. 1380 el término ante quem. De acuerdo con esto y ateniéndonos al tamaño, posición y fisonomía de los diferentes elementos de la filigrana, estas son las variantes más similares: Briquet 7376 (1351-61), 7358 (1376), 7359 (1377); Piccard 594 (1350), 586, 590 (1357); 585 (1360), 657 (1361), 605, 670, 675 (1362); 659 (1364), 601 (1375); Likhachev 342 (1358), 2040 (1360-75); Mosin 4318 (1355-6), 4333 (1358), 4355 (1361), 4347, 4369, 4375 (1360-70); 4374 (ca. 1370), 4376 (ca. 1360-1375). ${ }^{13}$ Con respecto al arco, pese a ser una filigrana muy frecuente, al igual que la del fruto, la figura utilizada en nuestro códice se diferencia principalmente por una ondulación del lomo menos acusada y un ángulo de apertura más amplio de la disposición triangular de la cuerda. Con estas características el periodo en el que se registran las variantes más afines a la nuestra es muy similar al estimado para la filigrana del fruto (1348-87): Briquet 781 (1348-51), 804 (1360-80); Piccard 1729 (1349), 1670 (1355), 1702 (1359), 1527 (1362), 1506 (1379), 1524 (1386-87); Mosin 323 (1348), 361 (1360-70), 369 (1370-80); Likhachev 2000 (1350-1380). ${ }^{14}$ 
Los bifolios en pergamino (fols. 1-26, 27-54, 55-72, 73-90, 91-110), usados como cubiertas de los cinco primeros cuadernos, son de calidad medio-baja, y en dos casos (fols. 54 y 110) se aprecia la curvatura próxima a las extremidades del animal del que procede el cuero empleado. Según lo esperable, se reservó siempre el lado de la carne para la cara interior del bifolio, y la pars pilis, más oscura, como cubierta exterior.

En cuanto a las tiras membranáceas de refuerzo, al menos en el caso de los dos últimos cuadernos (fols. 171-172 y 183-184), se trata de un material reaprovechado. En ellas se puede observar una notación musical con pneumas en el recto y verso de la parte izquierda de la tira, mientras que en la parte derecha (tanto en el recto como en el verso) se pueden leer las siguientes secuencias: ${ }^{15}$ "semen glorificate eum Annunciabitur" (fols. 171v-172r, 2r), "es qui uidebant me aspernabantur" (fols. 171v-172r, 2v); "[---] num laudate eum uniuersu" (fols. 183v-184r, 2r), "obprobrium hominum et abiectio plebis Omn" (fols. $183 \mathrm{v}-184 \mathrm{r}, 2 \mathrm{v})$. Las letras $<\mathrm{A}>\mathrm{y}<\mathrm{O}>$ son capitales y de alto abarcan dos o tres líneas. Ambos fragmentos son continuación el uno del otro ("...obprobrium hominum et abiectio plebis Omn|es qui uidebant me aspernabantur...", "...[domi] num laudate eum universu | semen glorificate eum annunciabitur...") y parecen pertenecer a un salterio latino ${ }^{16}$ del que no puedo precisar fecha (ss. XIV-XV).

Las dimensiones de la página son 295 x $220 \mathrm{~mm}$ (fol. 91), con una caja de escritura de 228 x $180 \mathrm{~mm}$ (fol. 76), distribuida a dos columnas de $228 \times 84 \mathrm{~mm}$ (fórmula Lemaire: $17+84+12+84+26$ ) y un número variable de líneas por columna, dependiendo del copista implicado, entre 28-29 (fols. 2r, 69r; calígrafo A) y 31-36 (fols. 143r, 159v; calígrafo B). Se utilizó el mismo esquema de pautado en todos los cuadernos, con únicamente el trazado de las directrices verticales y horizontales que enmarcan la caja de escritura y las columnas (Fig. 5). Los extremos de las cuatro directrices sobresalen y se extienden casi hasta los bordes de los márgenes. Parece que el pautado se trazó a punta seca y por el método de presión (por lo que la hendidura se imprimiría por lotes de pliegos y no uno a uno), lo que explica que en algunos casos la marca sea muy notoria y en otros prácticamente indistinguible. Son perceptibles las perforaciones en los cuatro márgenes. 
FIG. 5

Pautado del ms. HSA, HC397/573

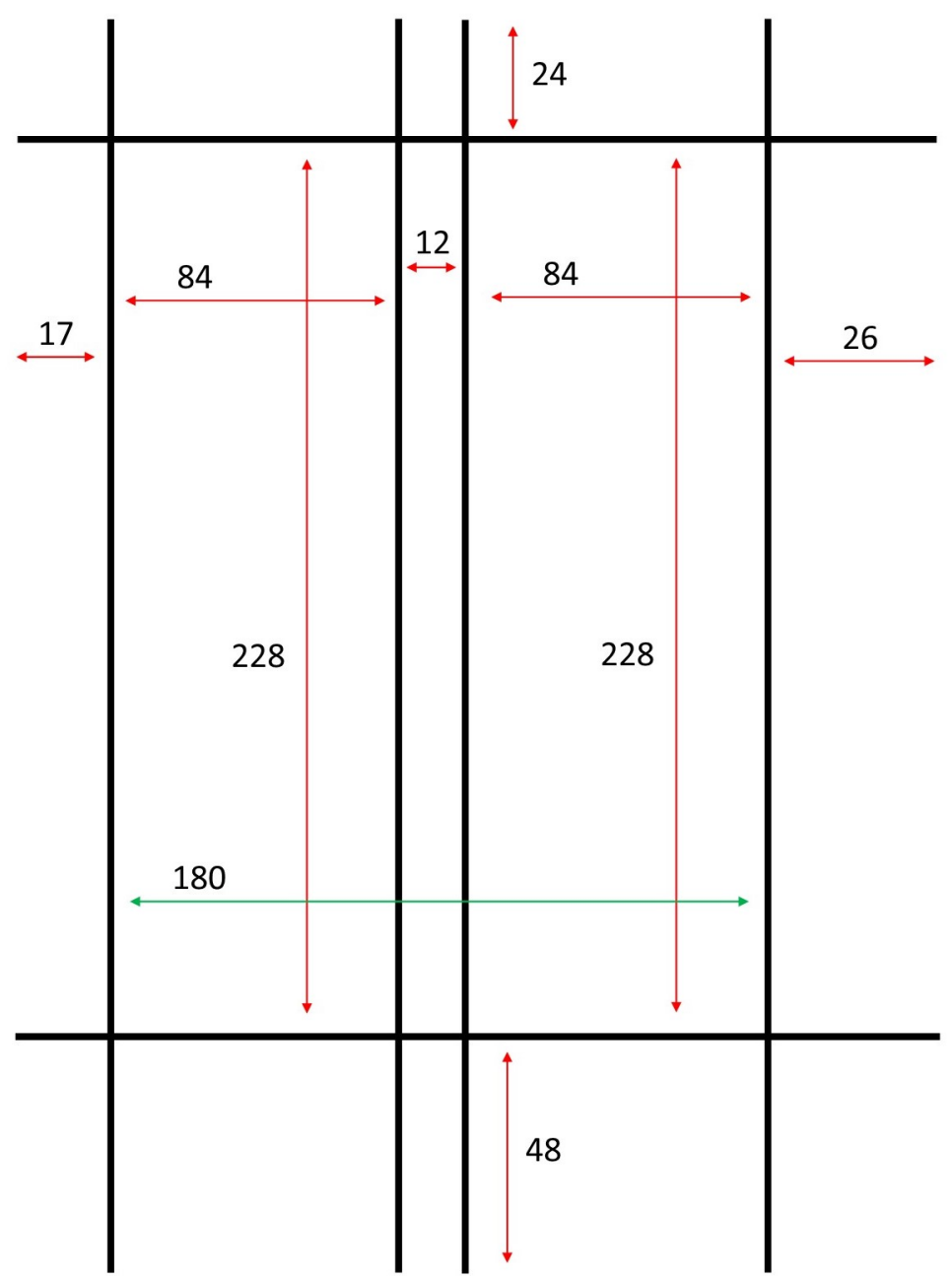

\section{ESCRITURA Y REVISIÓN DEL TEXTO}

Contrariamente a lo que indica García y García (1963b, p. 270), no hay una única mano responsable de la copia de este manuscrito, sino que trabajaron, al menos, dos calígrafos principales: uno en los cinco primeros cuadernos (calígrafo A: fols. 4va.21-110v; Fig. 6) y otro en los cuatro últimos (calígrafo B: fols. 111r, 129va, 26-185v; Fig. 7). Participan, además, dos o tres copistas auxiliares: uno en los primeros folios (calígrafo C: fols. 1-4va.20; Fig. 8) y otros dos (o tal vez uno solo) en el cuaderno central e inicio del séptimo (calígrafo(s) D-E: fols. 111v-114r, 114r-129va.23; Fig. 9). De manera puntual también se registra un cambio de mano en el fol. 29vb (ls. 1-11), cuya escritura es similar a la del calígrafo C. Aunque hay notables diferencias en el grado de cursividad y velocidad del trazado - los calígrafos B, C y D-E presentan una escritura más pausada y menos cursiva frente a la de $\mathrm{A}$-, la modalidad no textual usada en este códice parece responder a las características de la gótica cursiva aragonesa de transición a la bastarda, en su modalidad usual, especialmente en el caso de los calígrafos A, C y D-E. 
FIGS. 6 Y 7

Calígrafos A (fol. 81vb) y B (fol. 146va)

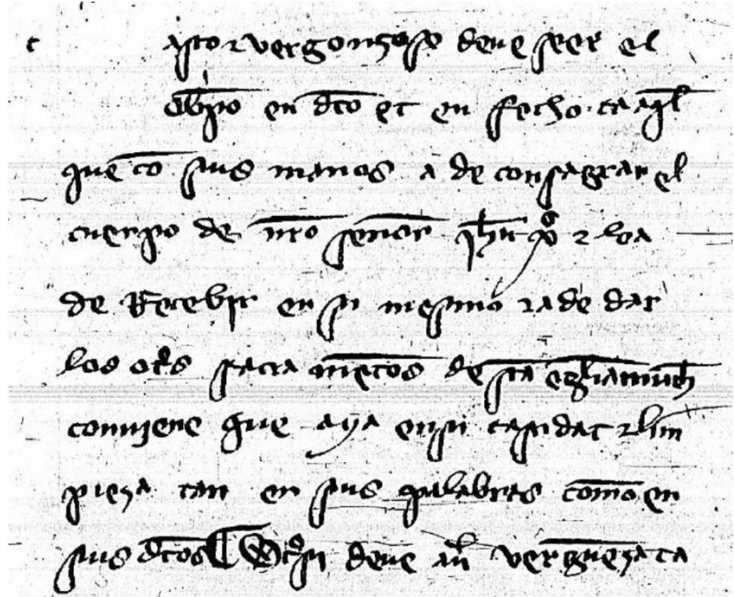

s

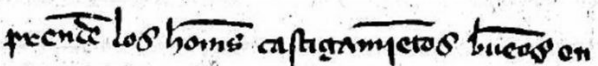
La stita como figm trie/rip grasered

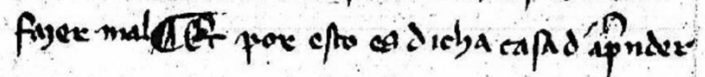

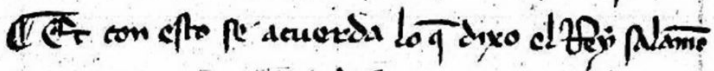

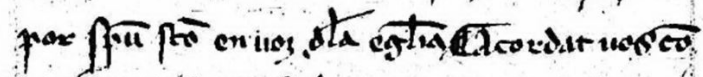

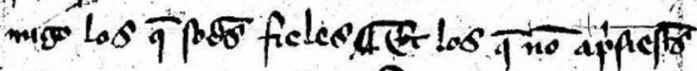

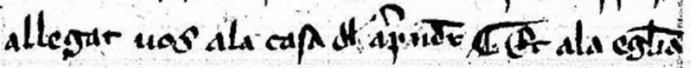

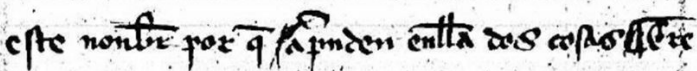

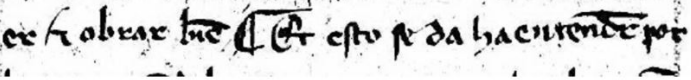

FIGS. 8 Y 9

Calígrafos C (fol. 3va) y D-E (fol. 155ra)
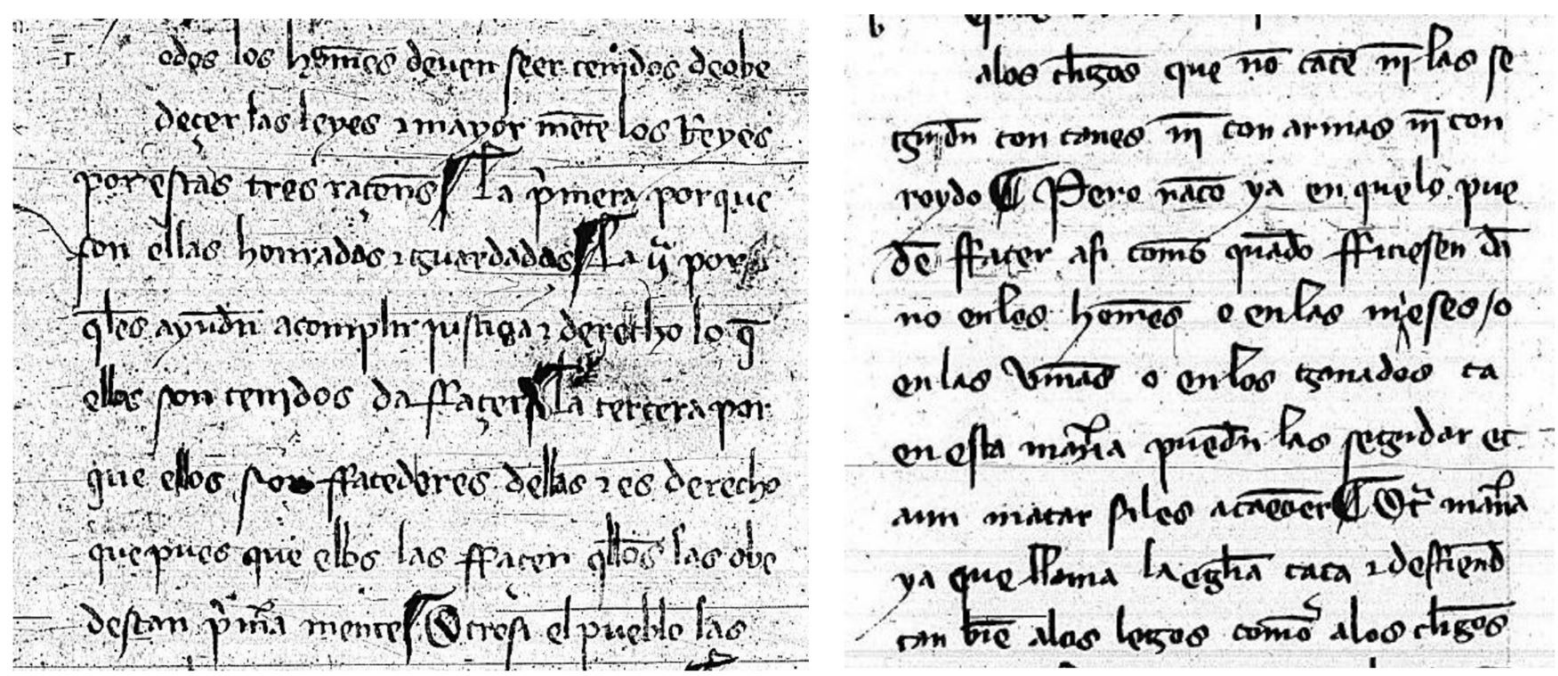

En la primera parte del códice (cuadernos 1-5), el trazado de A es más corriente y aéreo —-más descuidado, menos caligráfico y con más ligados-, y es habitual la oscilación en la cursividad y módulo de la escritura (ejs. fols. 20-21, 104ra). Esto se advierte en especial en las secciones copiadas en pergamino, al menos en los primeros casos (ejs. fols. 26-27, 54), quizás para aprovechar el máximo el espacio. La letra del calígrafo B es más compacta y menos cursiva, con un ductus más pausado y sin desarrollo de astas dobles. A diferencia de A, no presenta casi signos de corrección de entidad (cf. infra) y, pese a caracterizarse por un trazado menos fluctuante, no es infrecuente que la letra se apriete y el interlineado se reduzca sensiblemente en la parte final de las columnas (ejs. 156va, 158va, 160va, 172va, 173va). Este cambio de mano (A > B-D/E-B), coincidente con la transición entre cuadernos mixtos y los exclusivamente cartáceos, se produce en el interior de la ley $3^{3}$ del título $7^{\circ}$ De los clérigos (fol. 110vb-111r), y no es hasta el final del título $8^{\circ}$ De los religiosos (ley 31a, fol. 129va) cuando se retoma la labor de B tras su intervención puntual en el fol. 111r. Por su parte, D-E trabaja(n) entre los fols. 111v y 129va (títulos $7^{\circ}$ y 8 ); aunque no podemos asegurar si en realidad se trata de un solo copista o de dos, ciertas características gráficas (como el uso sistemático de astas simples o el remate angular de la $<\mathrm{l}>$ ) parecen diferenciar la escritura de los fols. 114rb-128va, más afín a la de A, de la de las 
primeras planas (fols. 111v-114ra), cuyo trazado es más próximo al de B. Por su parte, el trabajo del calígrafo $\mathrm{C}$ se reduce a los primeros folios (1-4va), incluyendo el índice de títulos y leyes, el prólogo, el primer título y el inicio del segundo. El cambio de mano $\mathrm{C}>\mathrm{A}$ se produce en la segunda ley del título $2^{\circ}$ De las costumbres (fol. 4va, 1.21).

La escritura notular empleada tanto en las anotaciones que completan o corrigen el texto como en la identificación de los títulos y leyes (situada en el margen de cabeza), es de módulo levemente inferior con respecto a la del texto base y es posible identificarla con la letra del calígrafo $\mathrm{B}$, que, por tanto, actuaría también como revisor y epigrafista. Por lo que se refiere a los reclamos, parece seguro que los que aseguran la continuidad de los cinco primeros cuadernos fueron apuntados por el calígrafo principal correspondiente (A: fols. 26v, 72v, 90v, 110v), con la única excepción del cuaderno 2 (fol. 54v), de trazado vertical, cuya letra se asimila más a la de B o D-E. La escritura de los restantes reclamos (fols. 126v, 143v, 161v, 181v) es idéntica a la del revisor (B).

En cuanto a la escritura decorativa, las rúbricas de prólogo, título y ley, así como los epígrafes (en el margen de cabeza), van siempre rotulados en tinta roja y en módulo ligeramente inferior al del texto base. No es infrecuente que el espacio reservado para la rúbrica resulte escaso (ejs. fols. 78v, 79r, 104r, 157v, 167v, 168r, $177 \mathrm{v}, 176 \mathrm{r}$ ); esto parece ocurrir con más frecuencia en los últimos cuatro cuadernos del códice, pues en esta sección la secuencia a destacar suele ser más extensa, lo que hace que se comprima la letra y el texto acabe invadiendo el intercolumnio o los márgenes de dobla y canal. En algún caso no se consignó la rúbrica (fol. 50v). La letra es, nuevamente, muy similar (si no es la misma) a la del segundo calígrafo principal (B), aunque en algunos casos tal vez se trate de otro copista con un trazado un poco más cursivo, como por ejemplo en los fols. 47v (similar a A) y 80r-v (similar a D-E). De ser esto cierto, el calígrafo B, además de ocuparse mayormente de la escritura del texto base de la segunda parte del códice (cuadernos 7-8) y de añadir algunos reclamos, también habría sido el responsable de revisar y corregir la copia y compilación del texto, de rotular la mayor parte de las rúbricas e incluir los epígrafes de las distintas (sub)secciones en el margen superior. Téngase en cuenta, además, que algunas de las correcciones mediante tachado, como se verá, se realizaron en tinta roja.

No se ejecutaron letras capitales, salvo en un caso en el fol. 26va (título 5, ley 29), pintada en rojo, con una altura de poco más de dos líneas y con un pequeño motivo cruciforme sin color en el centro. En cualquier caso, sí se reservaron los espacios correspondientes y se apuntaron casi siempre las letras de aviso (normalmente en tinta parda, pero a veces también aparecen en rojo con un trazo más grueso: fols. 82va, 102vab, 114v, 115r, $115 \mathrm{v}$ ). El manuscrito presenta con regularidad calderones curvos, pero también angulares (gammas); estos últimos, quizás fruto de una fase de rotulación o revisión posterior, parecen tener función de subdivisión secuencial. La presencia de calderones angulares se reduce en los últimos cuadernos del manuscrito, esto es, en aquellos confeccionados por el copista-revisor B. Tras los calderones curvos aparece siempre una mayúscula levemente coloreada en rojo.

El texto principal del manuscrito, especialmente en la primera mitad, fue objeto de una constante corrección por parte de los copistas y revisores que trabajaron sobre él. Se registran dos tipos fundamentales de enmienda: las de mayor entidad, que completan el contenido del texto base y se sitúan en los márgenes del folio; y las intervenciones de menor entidad que corrigen errores leves de copia y que o bien sobrescriben la secuencia errónea o bien añaden la secuencia correcta en el interlineado.

En el primer caso, la mayor parte de las correcciones de mayor entidad se ejecutaron en la sección copiada por el calígrafo A, que parece que trabajó con mayor velocidad y quizás con un menor grado de rigor a la hora de copiar del antígrafo o colacionar los diferentes materiales o modelos textuales implicados (fols. 1-110v, los 5 primeros cuadernos). Veamos algunos ejemplos: ${ }^{17}$ en el fol. 10 r (título $3^{\circ}$, ley $2^{\text {a }}$ ) se añade en el margen inferior la secuencia "de spiritu santo. El secundo que nascio de santa Maria uirgen. El iijo que recibio", omitida por error en la 1.16 de la primera columna ("El primero es que fue concebido [omisión] pasion et fue muerto $e$ soterado. el quarto que descendio alos jnfiernos...”, 1s. 15-18); en el fol. 46rb (título $5^{\circ}$, ley $73^{\mathrm{a}}$ ) 
se tachan las 1s. 9-11; en el fol. 69v (título $6^{\circ}$, ley $13^{\mathrm{a}}$ ) se añade en el margen inferior la secuencia "mas non sobre aquellos que so ellos son. Enpero cosas ya que el arcobispo [...]", omitida por error en la l. 9 de la segunda columna:

Ca bien asi como el patriarcha o el primado puede judgar $e$ poner pena alos arcobispos $e$ non alos obispos njn alos otros que les an de obedecer otro si el arcobispo a ese mesmo poder sobre los obispos [omisión] puede facer sin conceio $e$ sjn sabiduria de su patriarcha ode su primado asi como concilio. (fol. 69v)

A partir de aquí esta actividad correctiva se reduce drásticamente: se detecta ocasionalmente al final del $6^{\circ}$ cuaderno e inicio del $7^{\circ}$ (fols. 123ra, 124va, 125rb, 126va, 129rb), de la autoría de los copistas auxiliares DE, y es prácticamente inexistente en los cuatro últimos cuadernos (fols. 170r y 183r), lo cual sería esperable teniendo en cuenta que, como copista-revisor, el calígrafo B es probablemente el mayor conocedor del texto y de las dos fuentes implicadas, minimizando así el riesgo de error o laguna.

En cuanto a las correcciones de menor entidad, incluidas en el propio texto base, se registran a lo largo de todo el manuscrito, aunque, nuevamente, con más intensidad en la sección copiada por $\mathrm{A} .{ }^{18}$ No es infrecuente el tachado de secuencias enteras (a veces varias líneas) en el cuerpo del texto, especialmente en tinta roja (fols. 31ra, 46rb, $\left.{ }^{19} 71 \mathrm{vb}, 79 \mathrm{ra}, 96 \mathrm{ra}, 99 \mathrm{va}, 99 \mathrm{vb}, 101 \mathrm{va}, 122 \mathrm{rb}, 124 \mathrm{rb}, 126 \mathrm{ra}, 127 \mathrm{rb}\right)$, y ocasionalmente en la misma tinta parda del texto base (fols. 92rb, 105ra, 108ra); a veces se acompaña un punteado circunscribiendo la forma errada (fols. 101va, 122rb; otras veces sin tachado: fols. 123rb, 125ra, 159vb, 173va).

La inexistencia aún de un estudio paleográfico y filológico exhaustivo del texto en su integridad nos impide conocer si estos u otros cambios de mano, correcciones, ampliaciones y otro tipo de intervenciones coetáneas responden sin más a la tarea de escritura y revisión rutinaria del taller responsable de la copia, o bien guarda relación en algún caso con la compilación de los diferentes materiales colacionados en el manuscrito.

\section{ENCUADERNACIÓN}

La encuadernación es muy antigua, del siglo xv según Faulhaber, de piel color crema sobre cartón hecho con varias hojas de pergamino, muy apolillado (1983, p. 226). Las dimensiones de las cubiertas son $282 \times 220$ $\mathrm{mm}$ (4 mm de grosor, $60 \mathrm{~mm}$ el lomo). La inscripción del tejuelo, muy deteriorada, dice lo siguiente: "Fuero Antiguo de Teruel [.] de Sepulbeda", por lo que no sabemos si es una identificación errónea del contenido o si se trata de una encuadernación reaprovechada. ${ }^{20}$

En el interior de las gruesas cubiertas de la encuadernación, parcialmente carcomidas por la polilla, es posible observar cómo se utilizaron diferentes hojas de pergamino y papel para hacerlas más robustas (Fig. 10). Es prácticamente imposible leerlas porque las capas internas de las cubiertas no están muy separadas y por la destrucción del soporte debido a la carcoma, pero la letra utilizada en ellas en algunos casos no parece muy posterior a la de la confección del manuscrito (finales del s. xiv - primera mitad del xv). El tenor de esos textos es mayormente de naturaleza instrumental (documentos notariales o minutas). Solo es posible leer algunas palabras de uno de los recortes situado en el ángulo inferior externo de la capa posterior: "[---]nt [...] no es por [---] | [---] vender una haç[---] | [---] diziendo voz que lo [-] ve[---] | [---] voz la que [---] ve[---] | [---] si por ventura [...]". Por su parte, las capas internas de la cubierta anterior - que presenta un gran orificio central debido a la carcoma- apenas son visibles, aunque sí son reconocibles cartones y papeles con las mismas letras que en las capas internas de la cubierta posterior. 
FIG. 10

Interior de las cubiertas del ms. HSA, HC397/573

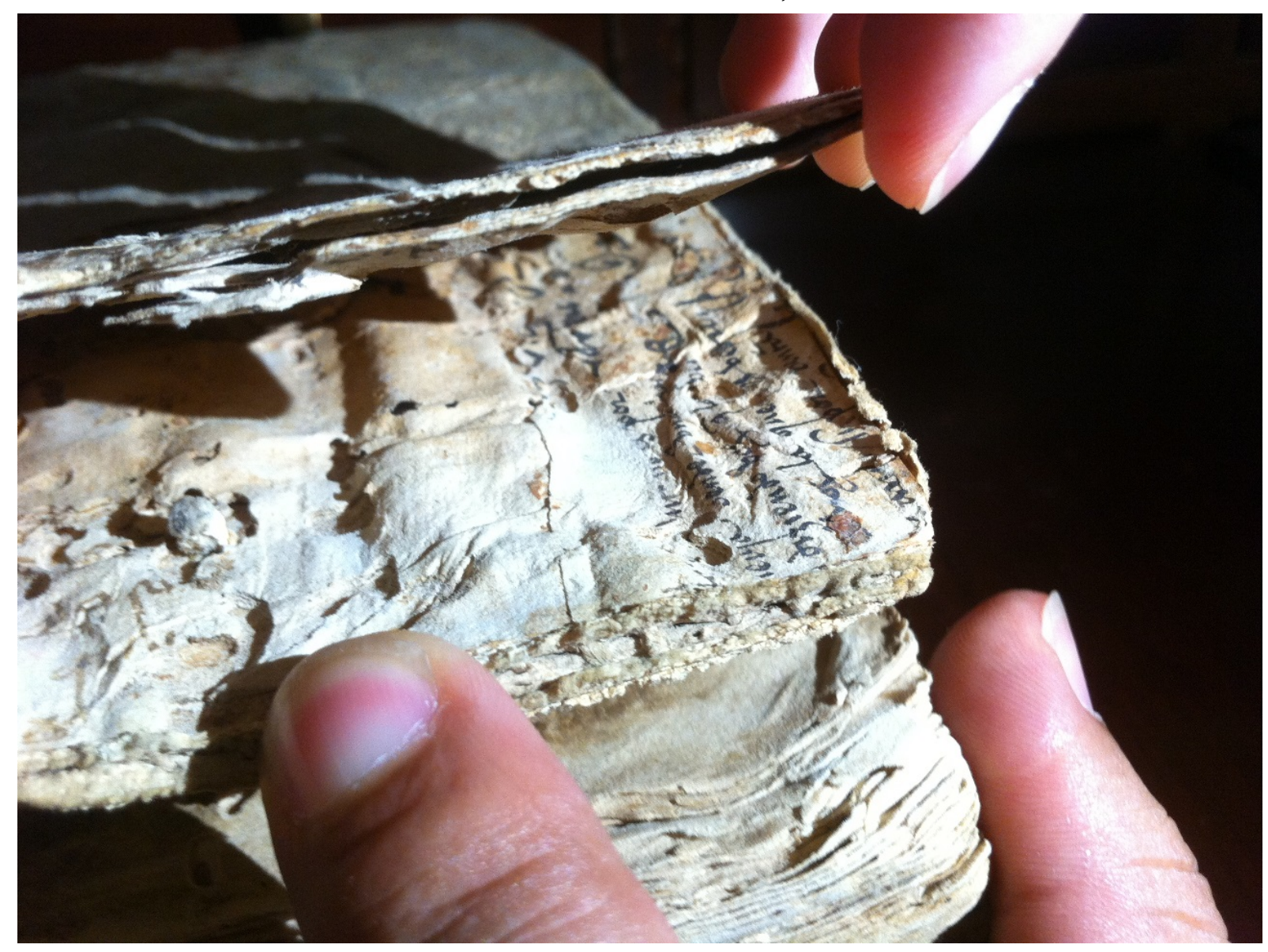

En las contracubiertas se adhirieron cuatro fragmentos de papel en los que se puede leer lo que parece un reparto de molino o similar de varios habitantes de alguna localidad turolense - tal vez Cella o Lanzuela - ${ }^{21}$ de letra coetánea o no muy posterior a la del texto base, de finales del XIV o primeras décadas del XV (cf. Faulhaber, 1983, p. 226; cf. infra n. 24). Las anotaciones aparecen dispuestas en tablas y en tres de los fragmentos - los de la cubierta anterior y el de la derecha de la cubierta posterior - se puede leer la parte superior del texto, donde se organizan en la primera fila de la tabla los siguientes conceptos encabezando cuatro columnas: trigo, centeno, ordio y auena (casi siempre acompañados de la forma "fs": fanegas); del cuarto fragmento no se conserva el extremo superior, mientras que de los otros el deterioro no deja ver parte de la tabla en la mitad superior. En la columna inicial del primer, segundo y cuarto fragmento aparecen los sujetos objeto de recuento:

cubierta anterior, primer fragmento:

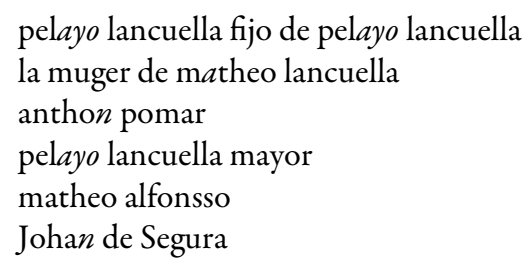

cubierta anterior, segundo fragmento (mutilado en la parte superior):

pedro martinez 


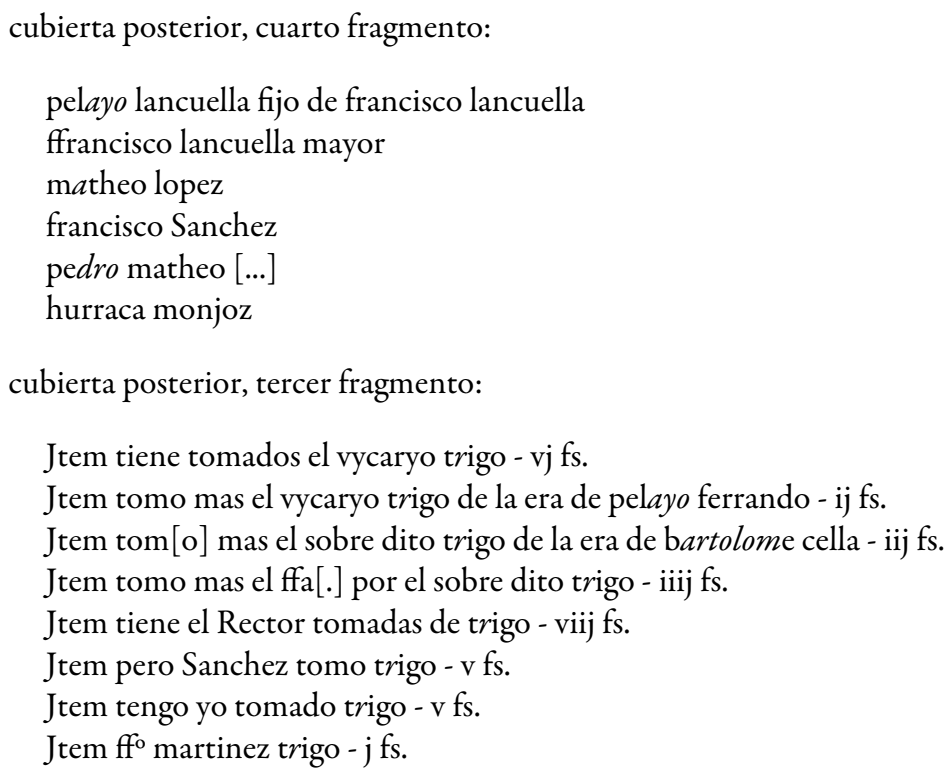

\section{Conclusiones}

El examen codicológico esbozado aquí - junto con un mínimo apunte referido a la configuración escriptolingüística del texto que se copia (cf. infra) - nos permite trazar las coordenadas espacio-temporales aproximadas en las que se habría confeccionado esta valiosa y aún poco conocida redacción mixta de la Primera Partida y el Setenario. Por una parte, de acuerdo con la cronología aproximada de las filigranas y al tipo de letra, parece seguro situar cronológicamente la confección del manuscrito en la segunda mitad del siglo XIV; ${ }^{22}$ quizás a comienzos del último tercio (ca. 1360-1380), teniendo en cuenta la gótica cursiva usual empleada por el copista principal (A) y la evolución de la figura de ciertas grafías como la $<$ ç>, la $<$ g $>$ o los diferentes alógrafos de la s y la $\mathrm{z}^{23}$

Por otra parte, de acuerdo con la adscripción aragonesa tanto de la escritura como de ciertas soluciones gráfico-lingüísticas, alternantes o sistemáticas, de los diferentes calígrafos implicados, especialmente A y C (ejs.: anyo, asin, atorgar, cayer, cone(s)cer, ensenyamiento, esti, fruyto, jutgar, marturiado, paç, peyor, qui 'conj. que', senyor, seyer, sobervioso, stablimiento, tracion, trayer, trebalar/trebaxar, viespra), ${ }^{24}$ podremos circunscribir con cierta seguridad el área del taller responsable de esta copia dentro del ámbito sociocultural y político de la Corona de Aragón; posiblemente en la zona más meridional del antiguo reino aragonés, en el entorno de la comarca turolense, si tenemos en cuenta también el texto de las contracubiertas del códice, que nos permite extraer información geográfica aproximada sobre la procedencia del manuscrito. ${ }^{25}$

Algunos de los principales rasgos codicológicos y paleográficos aquí esbozados (uso de cuadernos mixtos, tipo de letra, intervención de varios copistas, abundante actividad revisora y correctiva) parecen encajar con la naturaleza inconclusa y experimental del ensamblaje discursivo ensayado en el códice neoyorquino. Tal vez haya que poner en relación esta labor de copia y refundición con la pujante actividad de compilación y difusión de las Partidas operativa en la Corona de Aragón desde comienzos de la segunda mitad del siglo XIV y a instancias de Pedro el Ceremonioso (1336-1387), ${ }^{26}$ tal como demuestra, por una parte, la traducción al catalán de la Primera y Segunda Partida y su utilización como fuente en ciertas obras de caballería como el Tractat de cavalleria de Pere III o el Sumari de batalla a ultrança (véase ahora Sabaté i Marín y Soriano Robles, 2015 y en preparación; Avenoza, 2021); y por otra, la existencia de ejemplares del texto castellano en la Casa Real aragonesa (Pérez Martín, 1992, pp. 48-49, n. 161). 


\section{Fuentes DOCUMENTALES Digitales}

BDTEA-TNA = Gago, F. (Coord.).Biblioteca Digital de Textos del Español Antiguo. Textos NavarroAragoneses. Recuperado de http://www.hispanicseminary.org/t\&c/nar/index-es.htm

BETA = Faulhaber, Ch. B. (Dir.) (1997-). Bibliografía Española de Textos Antiguos. Berkeley:The Bancroft Library, University of California. Recuperado de https://bancroft.berkeley.edu/philobiblon/beta _es.html

BITAGAP = Askins, A. L-F. (Dir.) (1997-). Bibliografia de Textos Antigos Galegos ePortugueses. Berkeley: The Bancroft Library, University of California. Recuperado de https://bancroft.berkeley.edu/ph ilobiblon/bitagap_ga.html

BITECA = Avenoza, G., Soriano, L., y Beltran, V.(Dirs.) (1997-). Bibliografia de textos anticscatalans, valencians i balears. Berkeley: The Bancroft Library, University of California.Recuperado de https://bancr oft.berkeley.edu/philobiblon/beta_es.html

CHARTA = Almeida, B. (Coord.).Corpus Hispánico y Americano en la Red: Textos Antiguos.Recuperado de http://www.corpuscharta.es

CODEA = Sánchez-Prieto Borja, Pedro (Coord.).Corpus de documentos españoles anterioresa 1800. Recuperado de http://corpuscodea.es/

CORDE $=$ Real Academia Española (Banco de datos).Corpus diacrónico del español.Recuperado de ht tp://www.rae.es

GWA = Mosser, D. W., Sullivan, E. W., Hatfield, L., y Radcliffe, D. H. (Coords.) (1996-). The Thomas L. Gravell Watermark Archive. Recuperado de http://www.gravell.org

\section{REFERENCIAS}

Agudo Romeo, M. del M., Lapeña Paúl, A. I., y Rodrigo Estevan, M. L. (2007). Las fuentes: manuscritos y ediciones de los fueros de Teruel y Albarracín. En Tiempo de derecho foral en el sur aragonés. Los fueros de Teruel y Albarracín, vol. 1 (pp. 281-360). Zaragoza: El Justicia de Aragón.

Arias Bonet, J. A. (1972). Nota sobre el Códice neoyorkino de la Primera Partida. Anuario de historia del derecho español, 42, 753-756.

Avenoza, G. (2021). Las Partidas en catalán. En J. M. Fradejas Rueda, E. Jerez Cabrero y R. Pichel (Eds.), Las Siete Partidas del Rey Sabio. Una aproximación desde la filología digital y material. Madrid / Frankfurt: Iberoamericana / Vervuert, 97-101.

Balmaceda Abrate, J. C. (2008). Apuntes para el estudio del papel y las filigranas durante el siglo XV en la Corona de Aragón. Aragón en la Edad Media, 20, 103-116.

Briquet, Ch.-M. (1991 [1907]). Les filigranes: dictionnaire historique des Marques du Papier. Hildesheim / Vaduz: Georg Olms / A. R. Gantner, 4 vols.

Corral Díaz, E., y Pichel, R. (Coords.); Pichel, R., Garzón Fernández, M. A., Vázquez García, T., y García-Fernández, M. (2020). Guia para o estudo da prosa galega medieval. Santiago de Compostela: Xunta de Galicia, Centro Ramón Piñeiro para a Investigación en Humanidades (Col. ArGaMed, 3). Recuperado de http://www.cirp.ga 1/w3/publicacions/pub-0511.html

Craddock, J. R. (1981). La cronología de las obras legislativas de Alfonso el Sabio. Anuario de Historia del Derecho Español, 41, 365-418 [recogido en Craddock 2008: 43-101].

Craddock, J. R. (1986). The Legislative Works of Alfonso X, el Sabio: A Critical Bibliography. Londres: Grant \& Cutler.

Craddock, J. R. (1992). Los pecados veniales en las Partidas y en el Setenario: dos versiones de Graciano, Decretum D.25 c.3". Glossae: Revista de Historia del Derecho Europeo, 3, 103-116 
Craddock, J. R. (2001). The Partidas: Bibliographical Notes. In R. I. Burns (Ed.) y S. P. Scott (Trad.). Las Siete Partidas. Volume one. The Medieval Church. The world of clerics and laymen, vol. 1, pp. xli-xlviii. Philadelphia: University of Pennsylvania Press.

Craddock, J. R. (2008). Palabra de rey: selección de estudios sobre legislación alfonsina. Salamanca: Seminario de Estudios Medievales y Renacentistas.

Díez de Revenga Torres, P., y Puche Lorenzo, M. Á. (2003). Los Scriptoria medievales la amplificación como recurso en el Título IV de la Primera Partida. En A. Vera Luján, R. Almela Pérez, J. M. Jiménez Cano y D. Anunciación Igualada Belchí (Coords.). Homenaje al profesor Estanislao Ramón Trives, vol. 1, pp. 229-258. Murcia: Universidad de Murcia, Servicio de Publicaciones.

Domingues, J. (2021). La tradición medieval de las Siete Partidas en Portugal. En J. M. Fradejas Rueda, E. Jerez Cabrero y R. Pichel (Eds.), Las Siete Partidas del Rey Sabio. Una aproximación desde la filología digital y material, en prensa. Madrid / Frankfurt: Iberoamericana / Vervuert, 103-116.

Faulhaber, Ch. B. (1983). Medieval Manuscripts in the Library of The Hispanic Society of America: Religious, Legal, Scientific, Historical, and Literary Manuscripts. New York: The Hispanic Society of America, 2 vols.

Fradejas Rueda,J. M. (2021). Los testimonios castellanos de las Siete Partidas. En J. M. Fradejas Rueda, E. Jerez Cabrero y R. Pichel (Eds.), Las Siete Partidas del Rey Sabio. Una aproximación desde la filología digitaly material, en prensa. Madrid / Frankfurt: Iberoamericana / Vervuert, 21-35.

Friedmann, W. R. (1911). Las Siete Partidas del Rey D. Alfonso X, el Sabio. La primera Partida / Textkritische Untersuchung einer unveröffentlichen Handschrift des vierzehnten Jahrhunderts. Leipzig: Karl W. Hiersemann.

García y García, A. (1963a). Manuscritos jurídicos medievales de la Hispanic Society of America. Revista española de derecho canónico, 18(53), 507-559.

García y García, A. (1963b). Un nuevo códice de la Primera Partida de Alfonso X el Sabio. Anuario de Historia del Derecho Español, 33, 267-343.

García y García, A. (1986). La tradición manuscrita de las Siete Partidas. En A. Pérez Martín (Ed.), España y Europa, un pasado juridico común: actas del I Simposio Internacional del Instituto de Derecho Común, Murcia, 26-28 de marzo de 1985 (pp. 655-699). Murcia: Instituto de Derecho Común.

Iglesia Ferreirós, A. (1985). Reseña a Alfonso X el Sabio: Primera Partida (Ms. HC397/573), Hispanic Society of America. (Edición de) Francisco Ramos Bossini. Caja General de Ahorros y Monte de Piedad de Granada. Granada, 1984. Anuario de historia del derecho español, 55, 95-150.

Likhachev, N. P. (1994). Likhachev's watermarks: an English-language version (Eds. J. S. G. Simmons y B. Van Ginneken-Van de Kasteele). Amsterdam: Paper Publications Society, 2 vols.

Mateu Ibars, M. D. (1980). Colectánea paleográfica de la Corona de Aragón. Siglos IX-XVIII. II Láminas. Barcelona: PUB.

Mosin, V. A. (1957). Filigranes des XIII et XIV ss. Zagreb: Académie Yugoslave des Sciences et des Beaux, 2 vols.

O’Neill, J. (2016). El dinero, Archer M. Huntington y los fondos teatrales de la Hispanic Society of America. En F. B. Pedraza Jiménez, R. González Cañal y E. E. Marcello (Eds.), El dinero y la comedia española. XXVIII Jornadas de teatro clásico (Almagro 10, 11 y 12 de julio de 2014) (pp. 205-220). Cuenca: Ediciones de la Universidad de Castilla-La Mancha.

Panateri, D. A. (2016). La política en el discurso jurídico alfonsí. Una interpretación a partir de sus variantes textuales. Cuadernos de Historia del Derecho, 24, 187-202.

Panateri, D. A. (2017). El discurso del rey El discurso jurídico alfonsí y sus implicancias políticas. Madrid: Dykinson (Col. Historia del derecho, 54).

Panateri, D. A. (2018). Sapiencialismo y legalismo, una distinción útil para Las Siete Partidas. 7PartidasDigital. Edición critica digital de las "Siete Partidas". Recuperado de https://7partidas.hypotheses.org/1170

Panateri, D. A. (2020). El libro de derecho como bien indisponible. El discurso jurídico alfonsí y sus funciones. La Corónica, 48(2), 103-127. 
Panateri, D. A. (2021). ¿Qual deve ser el rey en suspalabras? Algunas precisiones sobre las Siete Partidas y su tradición manuscrita. En J. M. Fradejas Rueda, E. Jerez Cabrero y R. Pichel (Eds.), Las Siete Partidas del Rey Sabio. Una aproximación desde la filología digital y material. Madrid / Frankfurt: Iberoamericana / Vervuert, 59-71.

Panateri, D. A. y Tostes, R. (2021). El ms. HC 397-573 de la Hispanic Society: algunas hipótesis de trabajo. Olivar. Revista de literatura y cultura españolas, 21(34).

Pérez Martín, A. (1992). La obra legislativa alfonsina y puesto que en ella ocupan las Siete Partidas. Glossae: Revista de Historia del Derecho Europeo, 3, 9-63.

Pérez Martín, A. (2014). Las redacciones de la Primera Partida de Alfonso X el Sabio. Revista española de derecho canónico, 71(176), 21-37.

Piccard, G. (1961-1980). Die Wasserzeichenkartei Piccard im Hauptstaatsarchiv Stuttgart. Stuttgart: Kohlhammer, 14 vols.

Pichel, R. (2021). La recepción de las Siete Partidas en la Galicia bajomedieval. En J. M. Fradejas Rueda, E. Jerez Cabrero y R. Pichel (Eds.), Las Siete Partidas del Rey Sabio. Una aproximación desde la filología digital y material. Madrid / Frankfurt: Iberoamericana / Vervuert, 117-133.

Puigdengolas, J. (2019). Passer le pouvoir: Modalités de réécriture dans le Setenario d'Alphonse X. En V. LamazouDuplan (Dir.), Écritures du pouvoir. Les cultures politiques dans la Péninsule Ibérique et au Maghreb (VIIIèmeXVìme siècle) (pp. 73-85). Bordeaux: Éditions Ausonius.

Puigdengolas, J. (2021). Notas sobre las relaciones literales entre el Setenario y las Siete Partidas. En J. M. Fradejas Rueda, E. Jerez Cabrero y R. Pichel (Eds.), Las Siete Partidas del Rey Sabio. Una aproximación desde la filología digital y material. Madrid / Frankfurt: Iberoamericana / Vervuert, 59-71.

Ramos Bossini, F. (1984). Primera Partida (Ms. HC397/573), Hispanic Society of America. Granada: Caja General de Ahorros y Monte de Piedad de Granada.

Real Academia de la Historia (1807). Las siete partidas del rey Don Alfonso el Sabio. Madrid: Imprenta real.

Rodríguez Velasco, J. (2010). La urgente presencia de las Partidas. La corónica, 38(2), 99-135.

Ruiz García, E. (2002). Introducción a la codicología. Madrid: Fundación Germán Sánchez Ruipérez.

Sabaté i Marín, G., y Soriano Robles, L. (2015). La cavallería a la Corona d'Aragó: tractats teòrico-jurídics de producció pròpia. eHumanista, 31, 154-170. Recuperado de https://www.ehumanista.ucsb.edu/sites/secure.lsit.ucsb.edu. span.d7_eh/files/sitefiles/ehumanista/volume31/ehum31.ms.sabate.pdf

Sabaté i Marín, G. y Soriano Robles, L. (en preparación). Les Partides del Rei Savi a Catalunya.

Serrano Montalvo, A. (1995). La población de Aragón según el fogaje de 1495. Zaragoza: Institución Fernando el Católico.

Valls i Subirà, O. (1970). El papel y sus filigranas en Catalunya (Monumenta chartae papyraceae historiam illustrantia, 12). Amsterdam: The Paper Publication Society, 2 vols.

\section{Notas}

1 Este trabajo se enmarca en los proyectos de investigación 7PartidasDigital (MCI/FEDER, FFI2016-75014-P / PID2020-112621GB-I00) y "HERES. Patrimonio textual ibérico y novohispano. Recuperación y memoria" (CM, 2018T1/HUM-10230). Una primera versión de este trabajo se mostró en el blog de 7PartidasDigital (https://7partidas.h ypotheses.org/1257).

2 Mi más sincero agradecimiento a John O’Neill, a Vanessa Pintado y a Fabián Landi - requiescat in pace - por las facilidades de consulta del códice en la Hispanic Society, especialmente en lo que respecta al estudio de sus filigranas y de la estructura fascicular. Agradezco, también, las orientaciones de José Manuel Fradejas Rueda (UVA), Pedro SánchezPrieto Borja (UAH) y Víctor Caballero Gómez (UCM/UAH/US).

3 Agradezco de nuevo a John O'Neill la rápida consulta del ejemplar de dicho folleto conservado en la HSA.

4 En el catálogo figura la cifra: "28 000".

5 "A critical and philological investigation of the manuscript will be published with this catalogue / Un examen crítico y filológico se publicará en un folleto particular". 
6 De acuerdo con O'Neill, 2016, p. 212, entre 1904 y 1914 Huntington compró casi 200.000 manuscritos y libros raros y modernos hispánicos, que le fueron ofrecidos en una treintena de catálogos impresos preparados por Hiersemann.

7 Con independencia de la redacción que transmitan, de la Primera Partida conservamos en la actualidad, al menos, 23 testimonios: quince castellanos (Fradejas Rueda, 2021), siete gallego-portugueses (la mayor parte fragmentarios; Domingues. 2021; Corral y Pichel (Coords.), 2020, pp. 135-188; Pichel 2021) y uno catalán (Avenoza, 2021).

8 Sobre la evolución y relación entre estas dos tendencias o tradiciones discursivas, así como otras cuestiones relacionadas, véanse, entre otros, los ensayos de Daniel Panateri 2017, 2018, 2020, 2021, así como el trabajo publicado en coautoría con Rogerio Tostes en este mismo volumen.

9 Véanse ahora los recientes ensayos de Johan Puigdengolas $(2019,2021)$ en torno a la vinculación entre el Setenario y las Siete Partidas.

10 Algunos insólitos, como la ausencia del índice de títulos y de secuencias enteras por salto de igual a igual.

11 "Sientese" (54v) > "sintiese" (55r), "postulaçion" (72v) > "[P] ostulaçion" (73r, falta la capital), "ffaçer sin" (126v) > "ffacer sin" (127r), "fiestas enlas capiellas" (143v) > "fiestas en las capiellas" (144r). El reclamo del fol. 161v se copia sin variaciones como rúbrica en $162 \mathrm{r}$.

12 Se registran cinco corondeles con la siguiente distribución espacial aproximada: 30-49-42-42 (filigrana del fruto tipo 1), 40-40-50-40 (filigrana del fruto tipo 2), 40-50-40-40 (filigrana del arco). La distancia entre puntizones oscila entre 3 y $4 \mathrm{~mm}$.

13 En los repertorios de filigranas alemanas (WZIS: https://www.wasserzeichen-online.de/wzis) y austríacas (WZMA: http://www.wzma.at/) nos encontramos con una cronología muy similar (ca. 1361-80): WZIS DE5580Clm7544_4 (1361), WZIS DE0960-Mlf387_109 (ca. 1370), WZIS DE5580-Clm604_X (1374), WZIS DE3315GM19.C.II._273 y 285 (ca. 1380); WZMA AT $8500-3152$ 76 y 87 (1363), WZMA AT5000-317_112 (1370-80), WZMA AT2000-68_44 (1375-80). Registramos en WZIS otras tres filigranas muy similares (AT5000-251_5, AT5000-293_137 y AT5000-317_112) datadas en el último tercio del siglo xiv.

14 A estas podemos añadir WZIS NL8370-PO-123689 (1350, Utrecht) y GWA Bow.244.1 (1369, Lyon).

15 No reproduzco la separación original de las letras, que se corresponde con la notación musical.

16 Vid. http://cantusindex.org/id/g00848k.

17 Las correcciones registradas afectan a los fols. 10rab, 14va, 19va, 20rb, 27rb, 27va, 28va, 32va, 33vab, 37va, 42vb, 46rb, 46vb, 47rb, 50ra, 51ra, 62rab, 64ra, 67ra, 69vab, 80rb, 90rb, 91va, 94vb, 98ra, 98va, 100va, 103va, 104rb, 104vb, 107vab, 109ra, 110va.

18 Ejemplos: fols. 10vb, 16ra, $21 \mathrm{ra}, 22 \mathrm{ra}, 36 \mathrm{rb}, 37 \mathrm{rb}, 62 \mathrm{rb}, 64 \mathrm{rb}, 65 \mathrm{rb}, 69 \mathrm{ra}, 73 \mathrm{rb}, 78 \mathrm{vb}, 88 \mathrm{rb}, 90 \mathrm{va}, 91 \mathrm{vb}, 94 \mathrm{vb}, 97 \mathrm{rb}, 98 \mathrm{rb}$, 98vb, 99ra, 101rb, 115ra, 115vb, 117vab, 118rab, 119rab, 120rb (rúbrica), 122ra (rúbrica), 122rb, 123rb, 127rb, 148rb, $152 \mathrm{vb}, 157 \mathrm{rb}, 159 \mathrm{rb}, 159 \mathrm{vb}, 160 \mathrm{ra}, 174 \mathrm{va}, 175 \mathrm{vab}, 179 \mathrm{rb}$.

19 Con tachados diagonales en tinta parda.

20 De acuerdo con Agudo Romeo, Lapeña Paúl y Rodrigo Estevan (2007), se conservan varios códices latinos y romanceados del Fuero antiguo de Teruel, entre ellos dos de los siglos xiv y xv reencuadernados en el xix (cf. BETA texid 1185 y texid 2108).

21 De acuerdo con Serrano Montalvo, 1995, pp. 217-218 (http://www.peirones.com/cella.htm), a finales del siglo xv se registra la forma Lancuela — citada varias veces (junto con cella) en las contracubiertas del códice-, como apellido de varios vecinos residentes en la localidad de Cella (comarca Comunidad de Teruel); cf. infra n. 24.

22 A este mismo periodo apunta el uso de papel afiligranado de origen italiano y de los cuadernos mixtos en papel y pergamino. En cuanto a lo primero, de acuerdo con Balmaceda Abrate (2008: 105), a partir de mediados del siglo xiv era prácticamente definitiva la sustitución del papel hispanoárabe por el de origen italiano en la Corona de Aragón. Por otra parte, la construcción de cuadernos mixtos, cuyo objetivo primordial era reforzar la consistencia del entramado fascicular (Ruiz García 2002: 146-147, 153, 357), parece ser más habitual en la segunda mitad del trescientos para los códices literarios y no solo para los de carácter administrativo o notarial (véase, como ejemplos coetáneos, la Historia troyana de Pedro I, ca. 1365-1369 - BITAGAP manid 1558 - , o la copia más antigua y próxima al autógrafo del Teŗ̧ del Crestià de Eximenis, fechada a finales del xiv -BITECA manid 1507-).

23 Véanse, por ejemplo, las láminas 147 (1360), 150 (1368), 154a (1377) y 155 (1382) de Mateu Ibars (1980).

24 Algunas de ellas son características o exclusivas en textos aragoneses o castellano-aragoneses, como el Fuero de Teruel, los Fueros de Aragón o la extensa producción de Juan Fernández de Heredia (corpus consultados: CORDE, CODEA, CHARTA y BDTEA-TNA [consulta 27/03/2018]). Conviene puntualizar que los ejemplos traídos aquí son solo una muestra de una pequeña cala en el texto original, ya que la consulta de la edición de Ramos Bossini (1984) es absolutamente opaca en lo que concierne a la variedad lingüística, pues "castellaniza" la mayor parte de las soluciones gráficas y morfoléxicas de tradición (navarro-)aragonesa que ofrece el texto: anyo $>$ año, asin $>$ asi, atorgar $>$ otorgar, cayer $>$ caer, cone(s)cer $>$ conocer, ensenyamiento $>$ ensennamiento, esti $>$ este, jutgar $>$ judgar, marturiado $>$ martiriado, paç $>$ paz, peyor > peor, qui 'conj.' > que, senyor > señor, sobervioso > sobervio, stablimiento > establecimiento, tracion > traycion, trebalar/trebaxar > trabajar, viespra > vispera, etc. Esta valiosa información — cuando menos, a efectos de procedencia 
geográfica - no se refiere en las lacónicas observaciones (paleo)gráficas señaladas por García y García (1963b, p. 270) y Ramos Bossini (1984, p. lviii).

25 Aunque no se ha podido identificar con seguridad ninguna de las personas presentes en estos apuntes, la secuencia antroponímica "Francisco Lanzuela", como vecino o vecinos de la localidad de Cella, se registra, al menos, en dos documentos turolenses datados en 1387 y ca. 1420 conservados en el Archivo de la Comunidad de Teruel (Sección IV, doc. 5187 y Sección I, doc. 342, respectivamente), un arco temporal que parece encajar con la datación provisional de la letra de estas anotaciones y probablemente con la época en la que el manuscrito pudo ser (re)encuadernado. Agradezco a Víctor Caballero Gómez la indicación de estos datos. Más registros de Lanzuela o Cella en el Portal general de Documentos y Archivos de Aragón (https://dara.aragon.es/).

26 Por supuesto, el conocimiento de las Partidas en el reino aragonés era ya patente en las últimas décadas del siglo xiii, como demuestra su influjo en el Llibre de l'orde de cavalleria de Ramon Llull (ca. 1274-1276; BITECA texid 1683). 